\title{
Zeleno socialno delo in okoljska pravičnost na primeru vode in hidroenergije
}

\begin{abstract}
Zeleno socialno delo poudarja, da človeka ni mogoče ločiti od naravnega okolja, v katerem živi, (upoštevajoč floro in favno) in daje potrebno holistično razumevanje naravnih struktur in neživega okolja. Ciljzelenega socialnega delaje razvijanje socialnodelovne prakse, ki upošteva soodvisnost med obojim, človekom in naravo, redistributivno pravičnost in omogoča refleksijo oneenaki razporeditvi družbene moči. Okoljske katastrofe neenakomerno vplivajo na ljudi in bolj prizadenejo tiste, ki so ekonomsko najranljivejši; to se kaže v zdravju in duševnem zdravju ljudi. Članek analizira vprašanjeokoljske pravičnosti in okoljskegažalovanja, kisenanaša na ravnanjezvodnimi viri in uporabo hidroenergije. Tasicerveljaza »zelenoenergijo «, atrebaje upoštevatištudije, ki hidroenergijo vidijo kot vzrok okoljskega opustošenja. Zeleno socialno delo mobilizira skupnosti in posameznike, da opozarjajo na nove neenakosti. Članek se osredotoči na regijo Jugovzhodne Evrope, kjer je veliko nasprotovanj lokalnega prebivalstva proti gradnji novih hidroelektrarn. Podrobno opisan primer iz Bosne in Hercegovine, kjer so »pogumne ženske Kruščice « uspešno ustavile interese lokalnih in mednarodnih investitorjev in korporacij za gradnjo hidroelektrarn v lokalnem okolju in okrepile skupnostno solidarnost, ima veliko izpovedno moč tudi za zeleno socialno delo.
\end{abstract}

Ključne besede:zelenosocialno delo, hidroelektrarne, okoljske katastrofe, Jugovzhodna Evropa, okoljskia pravičnost, Kruščica.

Prof. dr. Darja Zaviršek poučuje in raziskuje na Fakulteti za socialno delo Univerze v Ljubljani, kjer je vodja Katedre za socialno vključevanje in pravičnost. Kontakt: darja.zavirsek@fsd.uni-lj.si.

Dr. Sonja Bezjak, je raziskovalka na Fakulteti za družbene vede, v prostem času vodi Muzejnorosti, nevladno organizacijo, kjer se v praksi poteguje za uresničevanje socialne in okoljske pravičnosti. Kontakt: sonja.bezjak@fdv.uni-lj.si.

\section{Green social work and environmental justice in the case of water and hydropower}

Green social work emphasizes that humans and the natural environment (taking into account flora and fauna) should not be separated and that a holistic understanding of human and natural structures is necessary. The goal of green social work is to develop social work practices that promote human-nature interdependence, redistributivejustice, and is critical to newsocial inequalities. Environmental disasters impact people unequally and affect those who are most economically vulnerable more severely; this is also reflected in people's health and mental health outcomes. The article presents an analytical example of environmental justice and environmental griefconcerning the water resources and the use of hydropower plants. Despite the latter being understood as "green energy", the article emphasizes the need to consider studies that see hydropower plants as a cause of environmental degradation. As green social work mobilizes communities and individuals to resist new inequalities, the article focuses on Southeast Europe, where there is much local resistance to the construction of new hydropower plants. The case from Bosnia and Herzegovina is described in detail, where the "brave women of Kruščica" successfully stopped the interests of local and international investors and corporations from building hydropower plants in the local area and strengthened community solidarity. This is a powerful story for understanding green social work.

Key words: green social work, hydroelectric power, environmental disasters, Southeast Europe, environmental justice, Kruščica.

Darja Zaviršek, PhD, is a professor and researcher at the Faculty of Social Work, University of Ljubljana. Contact: darja.zavirsek@fsd.uni-lj.si.

Sonja Bezjak holds a PhD in Sociology and is currently working as a researcher at the Faculty of SocialSciences, University of Ljubljana. As a volunteer, she runs a civic-societyorganization called Museum of Madness, where she is actively engaged in activities for social and environmental justice. Contact: sonja.bezjak@fdv.uni-lj.si. 


\section{Uvod}

Okoljske krize vplivajo na življenje posameznikov, skupnosti in celotnih družb in povzročajo uničevanje lokalnih okolij, ekonomskih panog, povezanih z biodiverziteto določenega okolja, ekonomsko pomanjkanje, bolezni, hendikep in preseljevanje ljudi, ki med begom pred okoljskimi problemi tvegajo svoja življenja. A to je šele začetek procesa okoljskih uničenj, ki bodo trajno vplivala na življenje ljudi. Socialno delo, ki se ukvarja prav z ljudmi v različnih življenjskih stiskah, se mora zato vključiti v globalne tokove razumevanj okoljske pravičnosti in se dejavno vključiti v procese, ki poskušajo preprečiti degradacije okolij in okoljske katastrofe.

$\mathrm{V}$ članku bova pojasnili koncept zelenega socialnega dela in nekaj ključnih pojmov v njem. Problem okoljskih katastrof bova razložili na primeru vode in njene uporabe v tako imenovani »zeleni« hidroenergiji, ki pa ni več dovolj »zelen« odziv na današnje okoljske težave. Prikazali bova, kako zelo pomembno je, da skupnost odloča o tem, kako se bo zaradi gradnje novih hidroenergetskih objektov spreminjalo lokalno okolje. Ljudje morajo soodločati o zelenih energijah, namesto da že tako degradirana in ekonomsko opustošena okolja postajajo objekt globalnega izkoriščanja. Ob tem je pomembna tudi ozaveščenost socialnih delavk in delavcev.

\section{Zeleno socialno delo}

Čeprav je v socialnem delu ekološka paradigma že dolgo znan koncept, ki se je v preteklosti nanašal na holistično razumevanje človeka, struktur in okolja, v Sloveniji ne poznamo ekološkega socialnega dela, ki bi bilo kritično do kapitalističnega ropanja in uničevanja okolja ter bi intersekcijsko in individualno reševalo problem in njegove posledice. Ena od prvih avtoric, ki so začele uporabljati sintagmo »zeleno socialno delo«, je bila Lena Dominelli (2012) ${ }^{1}$. V socialnem delu je znana kot začetnica feminističnega in antirasističnega socialnega dela, zato je tudi konceptu zelenega socialnega dela pridala kritično, antikolonialno in antikapitalistično razsežnost.

V Sloveniji smo se o zelenem socialnem delu v strokovni javnosti prvič pogovarjali na sedmem kongresu socialnega dela $(2019)^{2}$. Ugotovili smo, da je zanimanje zanj, pričakovano, izjemno majhno. Prepričali smo se o tem, da tudi v Sloveniji socialne delavke nimajo, kot poudarja Dominelli, strokovne samozavesti in da so premalo proaktivne pri določitvi meja socialnega dela in pri iskanju novih smeri v socialnem delu (Dominelli, 2012, str. 41). Nezanimanje za zeleno socialno delo je povezano tudi s tem, da je v postsocialističnih državah ekološka zavest slabo razvita in imajo tudi politični odločevalci velik problem z »zeleno politično voljo«. Posledica tega je, da so ljudje slabo organizirani, ko se postavijo po robu globalnim investitorjem, ki z lokalnimi

1 Lena Domnelli je s svojim znanstvenim opusom zelo vplivala tudi na slovensko tradicijo socialnega dela. To se najbolj kaže v magistrskem programu Socialna pravičnost in radikalne perspektive v socialnem delu, ki smo ga razvili na Katedri za proučevanje socialne pravičnosti in vključevanja na Fakulteti za socialno delo.

Kongres je konceptualno vodila omenjena katedra. 
politiki in drugimi vplivnimi akterji izkoriščajo naravne vire na račun ljudi in biodiverzitete. Večina ljudi o teh procesih ne ve veliko in se redko udeležuje okoljskih protestov.

Interes za zeleno socialno delo se je v Sloveniji povečal leta 2020, ko se je zgodilo več uporov proti političnim odločitvam, ki ogrožajo preskrbo s pitno vodo, proti vse pogostejšim okoljskim katastrofam, ki jih zagrešijo tuja ali slovenska podjetja, in proti gradnji novih hidroelektrarn v času, ko se zahodne države od njih že poslavljajo. Poglejmo si nekaj ključnih konceptov, ki jih zagovarjajo teoretiki vzdržnega razvoja in ki so se uveljavili tudi v zelenem socialnem delu.

\section{Zeleno socialno delo}

Zeleno socialno delo je smer socialnega dela, ki izhaja iz ugotovitve, da človeka ni mogoče ločiti od okolja, $v$ katerem živi, in da je potrebno holistično razumevanje obojega, vedenja človeka in struktur (kapitalizma, neoliberalizma). Okolje je, kot poudarja Dominelli (2012, str. 7), družbeno konstruirana entiteta, ki jo je treba spoštovati ves čas, tudi takrat, ko jo ljudje uporabljajo, da bi s posegi v okolje zadovoljili svoje potrebe in interese ter dosegli določene cilje. Cilj zelenega socialnega dela je razvijati socialnodelovne prakse, ki varujejo okolje (floro in favno) in človeka ter omogočajo razumevanje soodvisnosti med obojim. Človekovi posegi v okolje morajo temeljiti na načelih redistributivne pravičnosti in blaginje za vse ljudi, pri tem pa se je treba zavedati neenake razporeditve družbene moči. Zato je zeleno socialno delo vedno občutljivo za marginalizirane in revne ljudi ter se zavzema za antirasistične in druge antizatiralske prakse.

S takšnim odnosom lahko socialno delo vpliva na nekatere škodljive okoljske prakse, kot so okoljska degradacija, industrijsko onesnaženje, pretirana poraba virov pri nekaterih ljudeh, podnebne spremembe, migracije, ki jih povzročijo naravne katastrofe in konflikti med ljudmi, ki bodo postali vse hujši, saj je neonesnaženih naravnih virov vse manj.

\section{Okoljska pravičnost}

Koncept okoljske pravičnosti (ang. environmental justice) izhaja iz predpostavke, da naravni viri, ki jih je človek že zelo ogrozil in porabil za življenje in ustvarjanje dobička, niso enakomerno porazdeljeni med ljudmi in da nekateri ljudje živijo v izjemno opustošenih okoljih in niso deležni enakosti, ko gre za dostopanje do temeljnih virov (čista pitna voda, zrak in zemlja). Okoljska pravičnost pomeni zahtevo po porazdelitvi ekoloških tveganj in bremen, saj nimajo vsi ljudje enakega dostopa do naravnih virov in neokrnjenega okolja; je del prizadevanj za človekove pravice. Naravno okolje nikakor ni ločeno od socialnih kontekstov, zato ga moramo intersekcijsko razumeti v prepletenosti z razrednimi razlikami, spolnimi neenakostmi, etničnimi mejami, starostjo, hendikepom in drugimi človeškimi posebnostmi, ki generirajo neenakosti.

Revnejši in socialno ogroženi ljudje pogosteje živijo tam, kjer je velik hrup (hitre ceste, železnica), dihajo slabši zrak (ob tovarnah, sežigalnicah), pijejo 
slabo vodo in so zato bolj ogroženi kot premožnejši, da zbolijo in prej umrejo (Malovrh, 2020a; 2020b). Nekatere študije opozarjajo na primer na povezavo med demenco in življenjem ob hrupnih cestah in železnicah (Ferguson, 2017).

Tega se vse bolj zavedajo tudi ljudje, ki živijo na območjih, kjer mreže lokalnih in globalnih investitorjev načrtujejo gradnje hidroelektrarn in z njimi jezove ter vsakovrstne regulacije rek, ki bodo zarezale $\mathrm{v}$ življenje lokalnega prebivalstva. Lokalno prebivalstvo v okoljskih protestih v Jugovzhodni Evropi in Sloveniji proti gradnji novih hidroelektrarn izraža vse večjo zaskrbljenost. Hidroelektrarne namreč omejijo neposredni dostop lokalnega prebivalstva do vodnega vira, ljudje so prisiljeni spreminjati lokalno produkcijo, včasih postanejo okoljski begunci, ne morejo imeti dobička od zelenega turizma in sodelovati pri ekološki pridelavi hrane. Okoljske neenakosti zaznamujejo življenja ljudi za več generacij. Ženske so ob tem še posebej ogrožene, zato ni nenavadno, da so pri številnih protestih prav one zelo dejavne (Bezjak in Zaviršek, 2020).

Ponekod se je uveljavil koncept okoljskega rasizma (ang. environmental racism), ki se nanaša na okoljske politike, prakse in uredbe, zaradi katerih določene etnične skupine trpijo zaradi večje količine okoljskih bremen, imajo malo možnosti, da sodelujejo pri odločanju, ali pa so iz odločanja povsem izključene (Bullard, 2001). Koncept okoljskega rasizma opozarja, da je treba upoštevati vplive tako na okolje kot na ljudi in upoštevati glas lokalnega prebivalstva, ki je v primerih gradnje hidroelektrarn neposredno prizadeto. Če bi raziskali socialne in ekonomske vplive takih gradenj, bi se morali vprašati, kako bo gradnja vplivala na družbeno kohezivnost; kakšne so možne kulturne spremembe, ko gre za območja kulturnega pomena; kakšen je vpliv na nekmetijske ekonomske dejavnosti (ki dobivajo manj vladnih transferjev); kakšen je vpliv na zdravje ljudi; ali bo ljudem grozila preselitev (zaradi spremembe ravni vodne gladine in poplav); kakšna bo vrednost lokalno uporabljene oziroma prodane hidroenergije; kako se bo spremenila vrednost nepremičnin in transportnih možnosti za ljudi (Brown in dr., 2009, str. 306) ${ }^{3}$.

\section{Okoljske katastrofe, revščina in zdravje ljudi}

Okoljske katastrofe povzročajo obubožanje lokalnega prebivalstva na različnih delih sveta. Zaradi njih se povečuje revščina, ki je ena od najsurovejših oblik družbene neenakosti in pomeni nasilje nad posamezniki in posameznicami. Revščina vpliva na telesno in duševno zdravje ljudi. Ian Ferguson (2017), David Stuckler idr. (2017) in številni drugi opozarjajo na tesno zvezo med materialnimi problemi ljudi, duševno stisko in psihiatričnimi diagnozami. V ZDA in Grčiji se je v obdobju ekonomske krize po letu 2008 zelo povečalo število samomorov, ki jih imenujejo kar ekoñominski samomori, povezani z nezaposlenostjo; v Grčiji se je njihovo število zvišalo za kar 60 \% (Ferguson 2017, str. 13). Okoljske katastrofe bodo vplivale na prihodnjo revščino ljudi po vsem svetu, ta pa na slabšanje telesnega in duševnega zdravja ljudi.

3 Raziskovalci tudi poudarjajo, da bi bilo treba izračunati stroške celotnega življenjskega kroga jezu: fazo načrtovanja, izgradnjo, fazo delovanja in njegov vpliv na ljudi in na koncu tudi fazo odstranitve jezu. 


\section{Okoljski aktivizem}

Socialne delavke so lahko zagovornice pravic lokalnega prebivalstva, mobilizirajo in organizirajo ljudi v boju proti kapitalu in škodljivim politikam, spodbujajo skupnosti, lobirajo, da bi vplivale na politične odločevalce, in s svetovalnim in terapevtskim delom podpirajo posameznike in skupine, ki se znajdejo v materialni ali duševni stiski. V okoljski aktivizem so vključene socialne delavke z vsega sveta; njihovo število je sicer majhno, vendar imajo pogosto pomembno vlogo. Medha Patkar, na primer, je indijska socialna delavka in aktivistka za reke, ki je od sredine osemdesetih let 20. stoletja mobilizirala množične pohode in miroljubne proteste proti izgradnji jezu Sardar Sarovar, zaradi katerega so že preselili tisoče staroselcev in potopili prostrana kmetijska in gozdna območja ${ }^{4}$ (Leslie, 2005, str. 37).

\section{Okoljsko žalovanje}

Okoljsko žalovanje je posledica travmatične izkušnje izgube okolja, kot smo ga poznali, zaradi slabšanja okoljskih razmer po svetu. Danes so okoljskemu žalovanju najbolj izpostavljeni ljudje, ki imajo okrnjen dostop do pitne vode, čistega zraka in zemlje, ter znanstveniki, ki se vsak dan srečujejo s povečevanjem okoljske krize. Ti pripovedujejo o telesnih in čustvenih bolečinah, ki jih doživljajo, ko iz leta v leto na raziskovalnih terenih opazujejo vse večjo okoljsko degradacijo zemlje in uničevanje živali. Nekateri želijo ubežati okoljskemu žalovanju, izstopiti z določenega znanstvenega področja, drugi pa svetujejo, da mora človek postati »neobčutljiv« in robustnejši. V obeh primerih gre za odzive, ki nas lahko skrbijo. Socialne delavke se bodo $\mathrm{v}$ prihodnosti ukvarjale z ekološkim žalovanjem posameznikov in skupnosti; spodbujati bodo morale mobilizacijo ljudi za spremembe, vztrajanje pri okoljski pravičnosti in zelenem socialnem delu ter biti dejavne pri terapevtskih procesih travmatiziranih.

\section{Voda, hidroelektrarne in negativni učinki »zelene energije « na življenje ljudi}

Kako pomembno je za zagotovitev načel zelenega socialnega dela ravnanje $\mathrm{z}$ vodnimi viri? Delež porabe vode se razlikuje med regijami in državami. Razmerja med zalogami vode, obnovljivimi vodnimi viri ${ }^{5}$ in količino porabljene vode $\mathrm{v}$ prihodnosti bodo povečevala globalne neenakosti. ${ }^{6}$ Poleg regijskih razlik postaja, globalno gledano, pitna voda vse redkejša dobrina zaradi rasti prebivalstva, vse intenzivnejše porabe vode v kmetijstvu, industriji in gospodinjstvih in zaradi

4 Medha Patkar je leta 1992 za svoje delo prejela The Goldman Environmental Prize (b. d.).

5 Naravni obnovitveni procesi tekočih voda so na ravni države opredeljeni kot uspešnost ohranjanja stanja (notranjih, državnih) rek in podtalnice, ki se polnijo s padavinami (Ritchie in Roser, 2020).

6 Države OECD porabijo 20-25 \% svetovne vode; države BRICS okoli $45 \%$; države ROW pa skupaj 30-33\% (Ritchie in Roser, 2020). 
povečevanja temperature v ozračju. Po oceni Svetovne banke bi bilo od 100 do 400 milijonov ljudi izpostavljenih tveganju lakote, če bi se temperatura ozračja povišala za 2 stopinji Celzija, ena do dve milijardi ljudi pa bi lahko ostali brez ustrezne vode (Združeni narodi, 2019) ${ }^{7}$.

Ob vsem tem velja hidroenergija še danes v mnogih delih sveta (tudi $\mathrm{v}$ Sloveniji) za vzdržno ${ }^{8}$ razvojna strategijo, ${ }^{9}$ ki naj bi pripomogla h gospodarski rasti, zmanjšanju revščine in znižanju stroškov za proizvodnjo energije (Dogmus in Nielsen, 2019; Jakomin, 2019). Ob tem se pogosto molči o raziskavah, ki dokazujejo, da so njeni učinki prav nasprotni. Svetovna komisija za jezove je leta 2000 objavila poročilo, v katerem ugotavlja, da jezovi, ki spreminjajo reke in preusmerjajo njihov tok, vplivajo na človeška življenja, saj odločajo o tem, kdo bo imel dostop do vode in kako se bo spreminjalo življenje skupnosti (The Report of the World Commission on Dams, 2000). Nobena skrivnost ni, da so tudi v Sloveniji ${ }^{10}$ jezovi hidroelektrarn uničili biodiverziteto celotnih regij (na primer na Dravskem polju) in onemogočili dostop do pitne vode lokalnemu prebivalstvu (na Dravskem polju je voda iz pip neprimerna za dojenčke).

Najpogostejši škodljivi vplivi gradnje jezov za hidroelektrarne so: veliki stroški gradenj jezov; njihova velika obremenitev za biodiverziteto; neupoštevanje vpliva gradnje jezov na ljudi v večgeneracijski perspektivi (preselitve, razlastninjenje, izguba preživetvene in prehranske varnosti; brezposelnost, socialna anomija); ${ }^{11}$ premajhna ali nična pravica lokalnega prebivalstva do soodločanja; uničenje kulturne in zgodovinske dediščine (poplave mest, med zadnjimi na primer 10.000 let starega mesta Hasankeyf ob turškem jezu Ilisu na reki Tigris in uničenje slapov Sete Quedas na reki Teles Pires v brazilski Amazoniji, ki so imeli za domorodske etnične skupine Munduruku, Apiaka in Kayabi duhovni pomen) (več o tem v Bezjak in Zaviršek, 2020).

V 20. stoletju so jezovi simbolizirali gospodarski razvoj in po svetu je več kot 50.000 velikih jezov ${ }^{12}$ (Richter in dr., 2010, str. 15); največ so jih zgradili med letoma 1970 in 1975 (The Report of the World Comission on Dams, 2000 str. 9). Ker so na območju držav OECD številne vitalne reke že ujete v beton, se je gradnja jezov preselila na globalni jug, v industrializirajoče se države $v$

7 Pri upoštevanju razlik v naravnih posebnostih regij je pomembna komponenta sposobnost vodnega vira za obnavljanje. Južna Amerika ima v povprečju na prebivalca $30.428 \mathrm{~m}^{3}$ obnovljivih vodnih virov na letni ravni; Vzhodna Evropa jih ima $21.833 \mathrm{~m}^{3}$; Severna Amerika 12.537 $\mathrm{m}^{3}, \mathrm{v}$ Zahodni in Srednji Evropi je povprečno na prebivalca $4006 \mathrm{~m}^{3}$ obnovljivih vodnih virov na letni ravni, v severni Afriki pa samo $256 \mathrm{~m}^{3}$ (Ritchie in Roser, 2020). Izraz sustainable po navadi prevajajo kot trajnosten, $v$ tem članku pa uporabljava izraz vzdržen, saj v ospredje postavlja vprašanje vzdržnosti oz. nevzdržnosti delovanja sistema.

9 V Sloveniji gl. Energetski koncept Slovenije (2015), Akcijski načrt za obnovljive vire energije (2010) in Nacionalni energetski podnebni načrt (2018).

10 V Sloveniji za prvo veliko hidroelektrarno velja elektrarna Fala na Dravi. Obratovati je začela leta 1918.

11 Od okoli 472 milijonov ljudi, ki živijo manj kot 10 kilometrov stran od okoli 7000 velikih jezov, jih kar 91 milijonov živi ob najbolj poškodovanih rekah (Richter in dr., 2010, str. 31).

Veliki jezovi so tisti, katerih zid presega 15 metrov v višino (International Commission on Large Dams, b. d.). 
tropskem in subtropskem pasu in v države Vzhodne Evrope (Richter in dr., 2010; Scudder, 2017; Dogmus in Nielsen, 2019). ${ }^{13}$

Ključno vlogo pri glorifikaciji jezov in s tem hidroenergije imajo akterji globalne politične ekonomije, mednarodne finančne ustanove, Skupina Svetovne banke, Evropska investicijska banka, Svetovna trgovinska organizacija, vlade držav in številna strokovna združenja (npr. Mednarodno hidrološko združenje in Mednarodna komisija za velike jezove) ter vodilni makroekonomisti (Scudder, 2017, str. 429; Dogmus in Nielsen, 2019, str. 279). Tudi v slovenskem javnem govoru številni politiki, energetiki, ekonomisti in lobisti govorijo in pišejo o vodi in rekah kot neizkoriščenem potencialu obnovljivih virov energije in energetske jezove umeščajo v kategorijo »zelene energije« (Damjan in Babič, 2020). ${ }^{14}$

V številnih državah Jugovzhodne Evrope, kjer "premog predstavlja 97 odstotkov proizvodnje električne energije na Kosovu, okoli 70 odstotkov v Srbiji ter Bosni in Hercegovini, več kot polovico v Severni Makedoniji, približno polovico v Črni gori in okoli 28 odstotkov v Ukrajini« (Kopač, 2019), se zdi, da je hidroenergija edini odgovor na žgočo krizo onesnaženosti zraka in edini način energetskega razvoja. Zaradi premoga, ki ga uporabljajo elektrarne v Jugovzhodni Evropi, na tisoče ljudi umre prej, kot bi v ekološko neonesnaženem okolju. Nekatera glavna mesta, kot sta Priština in Skopje, veljajo za najbolj onesnažena mesta na svetu, Sarajevo pa je bilo leta 2020 prvo mesto po onesnaženosti zraka v svetovnem merilu (Fazlić, 2020).

Ni čudno, da zagovorniki hidroenergije tej pripisujejo pozitivne učinke, kot so izboljšanje kakovosti zraka, zmanjšanje porabe fosilnih goriv, upravljanje s poplavami, namakanje, zagotavljanje vode urbanim središčem, urejanje notranjega prometa, tehnološki napredek in ustvarjanje delovnih mest, torej zmanjševanje revščine (Ansar in dr., 2014; Polimeni in dr., 2014; Siciliano in dr., 2018).

\section{»Hrabre žene Kruščice «: okoljski protesti v Jugovzhodni Evropi in skupnostna akcija}

Mnogi raziskovalci so pokazali, da je voda del novodobnega korporativnega plenjenja (Gregorčič, 2017), in države globalnega juga, kamor sodijo tudi države Vzhodne Evrope, se zdijo primerna »lovišča« plenilskega kapitalizma (Videmšek, 2020).

Na območju nekdanje Jugoslavije in drugod po Jugovzhodni Evropi, v Sloveniji, na Hrvaškem, v Bosni in Hercegovini, Srbiji, Severni Makedoniji, Bolgariji, na Kosovem in v Albaniji, je načrtovanih okoli 2796 malih in velikih hidroelektrarn, številne na zaščitenih območjih velikih neokrnjenih rek (Sikorova in Gallop,

13 V Južni Ameriki načrtujejo ali že gradijo najmanj 2200 velikih jezov, med njimi naj bi jih bilo samo v Braziliji 1700. Kritični glasovi ob tem poudarjajo velikanske posledice na okolje in družbeno življenje, tudi nove socialne probleme, ki bodo ob tem nastali (Richter in dr., 2010, str. 16).

Na Ministrstvu za infrastrukturo je 12. julija 2017 potekala javna razgrnitev okoljskega poročila za akcijski načrt za obnovljive vire 2010-2020 (AN OVE) in dokumenta AN OVE. Predstavnica ministrstva je $v$ predstavitvi večkrat poudarila nujnost maksimalnega izkoriščanja slovenskih rek za pridobivanje hidroenergije (Bezjak idr., 2017). 
2015; Schwarz, 2017). Izmed njih naj bi se kar 1031 (37 \%) zgradilo v zaščitenih območjih, kot so narodni parki in območja Natura $2000^{15}$, v biosfernih rezervatih in območjih svetovne dediščine (Schwarz, 2017). Če te podatke umestimo v kontekst prej zapisanega, lahko ugotovimo, da bodo ti veliki energetski projekti imeli številne negativne vplive na življenje ljudi, vprašljive ekonomske prednosti in da je iz perspektive okoljske pravičnosti treba opozoriti na nevarnosti, ki jih prinašajo (Šeremet, 2018).

Zaprtje termoelektrarn sicer vpliva na zmanjšano onesnaženost zraka z žveplovim dioksidom in trdimi delci in merilec emisij toplogrednih plinov kaže obetavno prihodnost, a to ne pomeni, da so hidroelektrarne danes še vzdržni odgovor v luči zelenega socialnega dela. ${ }^{16}$

Velike hidroenergetske investicije, znane po netransparentnosti, zanimajo velika državna in manjša zasebna podjetja in banke, ki za gradnjo dobijo mednarodno podporo, najpogosteje Evropske banke za rekonstrukcijo in razvoj (EBRD) in Evropske investicijske banke, pa tudi Skupine Svetovne Banke. Evropska investicijska banka je v državah Jugovzhodne Evrope omogočila najvišji znesek neposrednega financiranja, 437 milijonov evrov za 5 elektrarn, ki so že zgrajene (Sikorova in Gallop, 2015, str. 14). Med drugimi investitorji prednjačijo predvsem avstrijska, nemška, italijanska in norveška energetska podjetja in kreditne agencije. Podjetje Austria Energy Easter Europe Hydro Power $\mathrm{GmbH}$ je na primer vključeno v sofinanciranje 27 projektov, od tega jih je 11 na okoljsko zaščitenih območjih (Sikorova in Gallop, 2015, str. 10). EBRD je vključena $v 51$ projektov zelene energije z 241 milijoni evrov, med njimi je 21 projektov na okoljsko zaščitenih območjih (ibid., str. 5). A zdi se, da je bilo v teh projektih veliko netransparentnosti, saj isto poročilo pravi:

Tako je na primer dokument o pritožbenih mehanizmih Evropske banke za rekonstrukcijo in razvoj (EBRD) leta 2013 sklenil, da je EBRD neustrezno ocenila projekt elektrarne Boškov most v makedonskem nacionalnem parku Mavrovo, projekt elektrarne Ombla, ki sodi v območje Natura 2000 na Hrvaškem, in projekt elektrarne Paravani v Gruziji. V vseh treh primerih je EBRD kršila lastno politiko, saj je neustrezno ocenila vpliv projektov na biodiverziteto, preden se je zanje odločila, in ni implementirala postopkov, ki bi zagotovili pomembno udeležbo javnosti pri odločitvi o prihodnosti projektov. (Sikorova in Gallop, 2015 str. 19)

Iz zapisanega je razumljivo, da so številni hidroenergetski projekti kljub temu, da so »zeleni«, v primerjavi s premogovno termoenergijo, trčili na odpor lokalnega prebivalstva (v Albaniji, Severni Makedoniji, Sloveniji, Srbiji in BIH), ki ni sodelovalo pri velikih odločitvah in ki si prizadeva za ohranitev prosto tekočih rek kot vira zelenega okolja, vzdržnega zelenega turizma in drugih elementov biodiverzitete, povezane s človeškimi dejavnostmi. Leta 2014 je lokalno prebivalstvo protestiralo proti gradnji elektrarne v nacionalnem parku Mavrovo, Makedonija

15 Več o omrežju izbranih varstvenih območij Natura 2000 v Toman (2013).

16 Avstrija je aprila 2020 kot osma članica EU zaprla svojo zadnjo termoelektrarno, pri Gradcu. Podobno načrtujejo tudi druge zahodne države v nasprotju s postsocialističnimi državami EU, ki so brez takih načrtov. Slovenija na primer predvideva zgolj zmanjšanje uporabe premoga za $30 \%$ do takrat, ko nameravajo druge zahodne države termoelektrarne zapreti (BA, 2020). 
ki sta jo nameravali financirati Svetovna banka in EBRD (pri tem še vztrajata) in proti elektrarni Ternove v Albaniji (N. N., 2014; Sikorova in Gallop, 2015).

V Bosni in Hercegovini so med okoljskimi protestniki najbolj znane »hrabre žene Kruščice« (pogumne ženske Kruščice), ki so s svojimi telesi branile reko na slabo razvitem področju osrednje Bosne. V občini Vitez so različni investitorji načrtovali dve mali hidroelektrarni na reki Kruščici, ki naj bi bili le neznaten del velikega hidroenergetskega projekta države, ki naj bi obsegal 278 hidroelektrarn; nekatere že delujejo, druge se načrtuje. Skrb zbujajoče je, da so od tega že danes 103 elektrarne v okoljsko zavarovanih območjih in na področjih z odlično kakovostjo rečne vode (Sikorova in Gallop 2015, str. 26).

Poleti 2017 so mediji začeli poročati o protestih lokalnega prebivalstva, ki je tedaj že tri mesece brez odmora na lokalnem mostu varovalo reko Kruščico pred prihodom kamionov in gradbenih strojev (Hayat Media BIH, 2017; E. M., 2017). Ljudje so se utaborili ob reki, da so lahko dan in noč preprečevali gradbincem začetek gradnje. Ko so avgusta 2017 območje Kruščice zavzeli oboroženi policisti, je izbruhnil nasilen spopad. Domačinke in domačini, ki se jim je pridružilo prebivalstvo Viteza, Zenice in Banja Luke, so poudarjali, da bi gradnja dveh malih hidroelektrarn uničila naravno okolje in biodiverziteto ter onemogočila ljudem dostop do izvira pitne vode, ki ga je tedaj uporabljalo okoli 150.000 ljudi v mestih Zenica in Vitez ter v vasi Kruščica. Okrnilo bi tudi izletništvo in turistični potencial kraja (Aljazeera Balkans, 2017). Lokalno prebivalstvo je začelo opozarjati na uničujoč trend gradnje stotin elektrarn po številnih rekah v državi. Poudarjali so, da bodo z gradnjo hidroelektrarn imeli dobiček le posamezniki, večini ljudi pa bosta ostala uničeno okolje in onesnažena pitna voda; onemogočen bo tudi zeleni turizem. Šećo Muslimović, starejši domačin, je dejal: »Če nam vzamejo vodo, nam vzamejo pravico do življenja!« Hata Hurem, ena od čuvark vode, je izjavila: "Oni nam hočejo vzeti našo vodo, ne le našo, temveč vodo vseh nas!" Amela Zukan, ena najvidnejših »pogumnih žensk Kruščice«, je zatrdila, da ne bodo nikoli dovolili izgradnje elektrarn, in poudarila, da bi gradnja uničila izvir zdrave pitne vode, to pa bi vplivalo na izbruhe bolezni in poslabšanje zdravja velikega števila ljudi, a prineslo dobiček posamez

Ime »Hrabre žene Kruščice« so ženske dobile po nasilnem policijskem napadu avgusta 2018, v katerem so ženske ubranile prehod čez most, ki so ga domačinke in domačini brez prekinitev blokirali okoli 300 dni in ki se od tedaj imenuje »Most hrabrih žena Kruščice« (Most pogumnih žensk Kruščice). Avgusta 2018 je policija nasilno umaknila protestnice in protestnike $\mathrm{z}$ vaškega mostu, a upor se je nadaljeval. Čeprav so posameznicam in posameznikom grozile tako regionalne oblasti kot investitorji, se niso umaknili. Številne organizacije so poudarjale izjemen pogum, ki so ga pokazale domačinke, s katerim so si izbojevale tudi politično zaupanje in prvič po letu 1995 postale izvoljene članice mestnega sveta (Brutalno postupanje specijalne policije nad ženama, 2017).

Investitorji, ki naj bi po enih informacijah dobili dovoljenje za gradnjo od uradnih oblasti, po drugi pa, da teh dovoljenj niso dobili, so nasprotno trdili, da bi hidroenergija prinesla regiji okoli pet milijonov evrov dobička na leto, a domačini so vedeli, da te dobičke ne bodo dobile skupnosti, temveč se bodo z njimi okoristili le posamezniki. 
Posledica pogumnega protesta predvsem žensk, ki jih je pravno-formalno, organizacijsko in tehnično podprl okoljski Centar za životno sredino Bosne in Hercegovine iz Banja Luke (ena najmočnejših okoljskih organizacij v državi), je bila odločitev okrožnega sodišča Novi Travnik, da razveljavi koncesijske pogodbe in dovoljenje za gradnjo hidroelektrarn (Friends of the Earth Europe, 2018; Save the Blue Heart of Europe News, 2018). Upor ljudi iz Kruščice je le del skupnih prizadevanj okoljskih organizacij, strokovnjakinj in strokovnjakov, da bi evropske institucije implementirale celostno razumevanje vplivov hidroenergetskih projektov na okolje in ljudi. To je že tudi skrajni čas, saj za reke v Evropski uniji velja, da jih ima kar 60 \% slab ekološki status (Chamberlain, 2018, str. 6).

Novembra 2018 je tako Evropski parlament tudi zaradi posledic protestov izdal resoluciji (Resolucija Evropskega parlamenta, 2018a; 2018b), s katerima je banke pozval k spoštovanju okoljskih standardov, in s tem implementiral korake k okoljski pravičnosti. Domačinkam in domačinom Kruščice je uspelo ustanoviti nevladno organizacijo, znotraj katere se zavzemajo za to, da bi območje pridobilo status zaščitenega območja, in so se povezali v Koalicijo za zaščito rek Bosne in Hercegovine. »Pogumne ženske Kruščice« so leta 2019 prejele tudi nagrado nemške organizacije EuroNatur.

Gregorčič (2017, str. 252) poudarja, da se prav v takih skupnih uporih kopiči novo znanje v skupnosti in o skupnosti ter skupno dobro, ki kaže na tisto, čemur sama pravi »epistemologija Juga« ali »epistemologija zatiranih «. Lokalno prebivalstvo in nevladne organizacije $\mathrm{v}$ skupnih prizadevanjih za okoljsko pravičnost pridobivajo »v telo vpisane« izkušnje o tem, da globalni investitorji v navezi z lokalnimi dobičkarji niso "napaka« ali "naključje«, temveč organizirana in sistematična veriga delovanja globalnega kapitalizma, ki je »harmonična« in »usklajena«. Pomen lokalne vednosti, del skupnega dobrega, oblikuje novo ozaveščenost in novo samozavest. Kako aktivno je na tem področju socialno delo, je treba raziskati na terenu samem ${ }^{17}$.

\section{Sklep}

Okoljski protestniki so do zdaj v Bosni in Hercegovini, Srbiji in Sloveniji uspešno ustavili številne hidroenergetske projekte na vitalnih rekah v teh državah (Nacionalni park Sutjeska, gradnja hidroprojekta na Neretvi, v kanjonu Ljuta, na reki Vrbas; okoljski boj za reko Muro). Okoljske organizacije, aktivne na Balkanu, namreč svarijo, da bodo jezovi, če jih bodo zgradili, škodovali nekaterim najbolj neokrnjenim evropskim sladkovodnim sistemom ter pustili hude in nepovratne posledice za sladkovodno biodiverziteto $\mathrm{v}$ regiji ${ }^{18}$. Zato se mora epistemologija zatiranih opirati na lokalna znanja in izkušnje ter se

17 Terensko delo je leta 2020 ustavila pandemija covida-19.

18

The Report of the World Commission on Dams (2000) ocenjuje, da so do zdaj po svetu zaradi gradenj hidroenergetskih objektov preselili že okoli 80 milijonov ljudi. Posledice preselitev se kažejo v razlastninjenju ljudi, izgubi preživetvene in prehranske varnosti, povečata se brezposelnost in socialna anomija, saj ljudje izgubijo čustvene, kulturne in duhovne samoumevne stike med seboj in z okolji, v katerih je živelo več generacij. 
hkrati vpeti v globalna gibanja; postati mora vidna po zaslugi "gostih opisov« pričevanj, da bi tako vplivala na novo ozaveščenost lokalnega prebivalstva in »zelene« globalne zavesti. V njej ima pomemben prostor tudi socialno delo.

V prihodnje bo upravičenost gradnje hidroelektrarn zaradi vse večjih potreb po električni energiji treba preverjati upoštevaje merila globalnega pomanjkanja vode, degradacije okolja in preživitvenih možnosti, izgube biotske in kulturne raznovrstnosti, socialne pravičnosti, vse povečevanja vrzeli med bogatimi in revnimi ter učinkovite rabe energije. Hidroelektrarne sicer ne porabljajo vode, a jo zadržijo v akumulacijskem jezeru za potrebe pridobivanja električne energije in $\mathrm{z}$ nasipi preprečijo »uhajanje« vode iz struge, to pa prekine vodni stik z rečnim zaledjem in spreminja značaj reke iz tekoče v stoječo. Da bi zmanjšali porabo električne energije, se moramo odpovedati zastarelim industrijskim panogam, ki porabijo veliko vode in električne energije, in jih nadomestiti s tistimi, ki upoštevajo učinkovito rabo energije. Velike energetske projekte je treba nadomestiti z manjšimi, preglednejšimi ter do ljudi in okolja prijaznejšimi projekti.

Vsi ti okoljski in človeški problemi zahtevajo meddisciplinarne in transdisciplinarne analize, pri katerih morajo poleg naravoslovcev, tehnikov in inženirjev sodelovati tudi socialne delavke, sociologi, antropologi in ekologi. Včasih o tem odločajo predvsem ljudje, ki so očitni zagovorniki hidroenergije, na primer pristojni za izdajanja okoljevarstvenih dovoljenj za hidroelektrarne, ki imajo malo znanja o kompleksnih družbenih vplivih gradenj jezov in o vplivu jezov na kulturno dediščino in kulturno krajino ter na zdravje ljudi, zeleni turizem in sodobne, ekološko vzdržne rešitve pridelave hrane. Poleg presoje vplivov na okolje potrebujemo torej nujno tudi presojo vplivov na družbo, na kar opozarjajo tudi številni strokovnjaki in strokovnjakinje, ki nasprotujejo gradnjam hidroelektrarn na reki Muri v Sloveniji. Zeleno socialno delo lahko ob tem odločilno pripomore k vzdržnim rešitvam.

\section{Viri}

Akcijski načrt za obnovljive vire energije (2010). Pridobljeno 31. 2. $2021 \mathrm{~s} \mathrm{https://www.}$ energetika-portal.si/dokumenti/strateski-razvojni-dokumenti/akcijski-nacrt-za-obnovljivo-energijo/

Aljazeera Balkans (2017). Mještani Kruščice protive se gradnji mini hidrocentrala [Video]. 30. 10. Pridobljeno 31. 1. $2021 \mathrm{~s} \mathrm{http://balkans.aljazeera.net/video/mjestani-kruscice-proti-}$ ve-se-gradnji-mini-hidrocentrala

Ansar, A., Flyvbjerg, B., Budzier, A., \& Lunn, D. (2014). Should we build more large dams? The actual costs of hydropower megaproject development. Energy Policy, 69. Pridobljeno 31. 1. $2021 \mathrm{~s}$ https://www.sciencedirect.com/science/article/abs/pii/ S0301421513010926

BA (2020). Avstrija rekla zbogom zadnji termoelektrarni na premog. Dnevnik, 20. april. Pridobljeno 3. 4. 2012 s https://www.dnevnik.si/1042927548

Bezjak, S., Slameršek, A., Bavec, N., Lorenčič, D., Tornar, T. \& Tornar J. (2017). Vzvišenost in aroganca uradnikov ter samoumevna podrejenost in ponižnost državljanov. Dnevnik, 2. september. Pridobljeno 3. 4. 2021 s https://www.dnevnik.si/1042783299

Bezjak, S., \& Zaviršek, D. (2020). Ženske so reko varovale podnevi, moški ponoči: okoljska pravičnost na področju hidroenergije. Časopis za kritiko znanosti, 48(279), 216-240. 
Bipasha, B. (2017). Renewable inequity? Women's employment in clean energy in industrialized, emerging and developing economies. Natural Resources Forum 41. Pridobljeno 31. 1. 2021 z DOI: $10.1111 / 1477-8947.12105$

Brown, P. H., Tullos, D., Tilt, B., Magee, D., \& Wolf, A., T. (2009). Modelling the costs and benefits of dam construction from a multidisciplinary perspective. Journal of Environmental Management, 90, 303-311.

Brutalno postupanje specijalne policije nad ženama (2017) [video]. Pridobljeno 31. 1. 2021 s https://www.facebook.com/recinemhe/videos/116211965708919/

Bullard, R. D. (2001). Environmental justice in the $21^{\text {st }}$ century: race still matters. Phylon, 49(3-4), 72-94.

Chamberlain, L. (2018). Eco-master plan for Balkan rivers (Poročilo Riverwatch in EuroNatur, Austria, Germany, PRESS-REVISION 1-2018 November 26-WEB). Pridobljeno 31. 1. 2021 s https://balkanrivers.net/sites/default/files/Eco-Masterplan\%20for\%20Balkan\%20 Rivers-PRESS-REVISION\%201-2018\%20November\%2026-WEB.pdf

Damjan, J., \& Babič, D. (2020). Kakšen naj bo prehod k nizkoogljični proizvodnji energije? Delo - Sobotna priloga, 1. 2., str. 12-13. Pridobljeno 31. 1. 2021 s https://www.delo.si/sobotna-priloga/kaksen-naj-bo-prehod-k-nizkoogljicni-proizvodnji-energije-272647.html

Dogmus, Ö. C., \& Nielsen J. Ø. (2019). Is the hydropower boom actually taking place? A case study of a South East European country, Bosnia and Herzegovina. Renewable and Sustainable Energy Reviews, 110. Pridobljeno 31. 1. 2021 s https://doi.org/10.1016/j. rser.2019.04.077

Dominelli, L. (2012). Green social work: from environmental crises to environmental justice. Cambridge: Polity Press.

E. M. (2017). Mještani Kruščice ne odustaju: nastavljamo borbu za naše pravo, ne želimo hidrocentralu. KLIX, 26. 8. Pridobljeno 31. 1. $2021 \mathrm{~s} \mathrm{https://www.klix.ba/vijesti/bih/mjestani-krusci-}$ ce-ne-odustaju-nastavljamo-borbu-za-nase-pravo-ne-zelimo-hidrocentralu/170825096

Energetski koncept Slovenije (2015). Pridobljeno 31. 1. 2021 s https://www.gov.si/zbirke/ projekti-in-programi/energetski-koncept-slovenije/

Fazlić, D. (2020). Sarajevo je najbolj onesnaženo mesto na svetu. 24UR. 13. 1. 2020. Pridobljeno 31. 1. $2021 \mathrm{~s} \mathrm{https://www.24ur.com/novice/tujina/sarajevo-je-najbolj-onesnaze-}$ no-mesto-na-svetu.html

Ferguson, I. (2017). Politics of the mind: Marxism and mental distress. Bookmarks, UK: Cambridge University Press

Friends of the Earth Europe (2018). Kruščica's 'brave women' celebrate stopping hydro dams. Pridobljeno 31. 1. 2021 s: http://www.foeeurope.org/kruscica-women-stop-hydrodams-191218

Gregorčič, M. (2017). Ženska, ki stoji za mitom: izris sodobnih zoperstavljanj globalnemu korporativnemu plenjenju. Časopis za kritiko znanosti, 45(269), 239-268.

Hayat Media BIH (2017). Mještani Kruščice ponovo blokirali lokalni put [Video]. 15. 9. Pridobljeno 31. 1. 2021 s: https://www.youtube.com/watch?v=kZRQna2jlYg

International Commision on Large Dams (b. d.). Dictionary. Pridobljeno 31. 1. $2021 \mathrm{~s} \mathrm{https://}$ www.icold-cigb.org/GB/Dictionary/dictionary.asp

Jakomin, M. (2019). HE prinašajo tudi pozitivne vplive na okolje. Naš stik, revija slovenskega elektrogospodarstva, 29. 4. Pridobljeno 31. 1. $2021 \mathrm{~s} \mathrm{http://www.nas-stik.si/1/Novice/}$ Clanki/tabid/208/ID/6605/HE-prinasajo-tudi-pozitivne-vplive-na-okolje.aspx

Kopač, J. (2019). Premog ubija prebivalstvo Zahodnega Balkana. DELO, 21. 3. Pridobljeno 31. 1. $2021 \mathrm{~s} \mathrm{https://www.delo.si/mnenja/gostujoce-pero/premog-ubija-prebivalstvo-za-}$ hodnega-balkana-162745.html

Leslie, J. (2005). Deep water: the epic struggle over dams, displaced people, and the environment. First Edition. New York: Farrar, Straus and Giroux.

Malovrh, P. (2020a). Onesnaženje lahko vpliva tudi na možgane in IQ. Delo, 3. 1. Pridobljeno 31. 1. 2021 s https://www.delo.si/novice/slovenija/onesnazenje-lahko-vpliva-tudi-na-mozgane-in-iq/ 
Malovrh, P. (2020b). Slovenija je kot veliko bolezensko bojno polje. Delo, 4. 1. Pridobljeno 31. 1. $2021 \mathrm{~s}$ https://www.delo.si/novice/slovenija/slovenija-je-kot-veliko-bolezensko-bojno-polje-261677.html

N. N. (2014). Gradnja HE jabolko spora med Makedonijo in Albanijo. Finance, 11. 2. Pridobljeno 31. 1. 2021 s https://izvozniki.finance.si/biznisplus/8830845/Gradnja-HE-jabolko-spora-med-Makedonijo-in-Albanijo

Nacionalni energetski podnebni načrt (2018). Pridobljeno 31. 1. $2021 \mathrm{~s}$ https://www.gov.si/ zbirke/projekti-in-programi/nacionalni-energetski-in-podnebni-nacrt/

Polimeni, J. M., Iorgulescu, R. I., \& Chandrasekara, R. (2014). Trans-border public health vulnerability and hydroelectric projects: the case of Yali Falls Dam. Ecological Economics, 98, 81-89.

Resolucija Evropskega parlamenta (2018a). European Parliament resolution of 29 November 2018 on the 2018 Commission Report on Albania (2018/2147(INI)).

Resolucija Evropskega parlamenta (2018b). European Parliament resolution of 29 November 2018 on the 2018 Commission Report on Montenegro (2018/2144(INI)).

Richter, B. D., Postel, S., Revenga, C., Scudder, T., Lehner, B., Churchill, A., \& Chow, M. (2010). Lost in development's shadow: the downstream human consequences of dams. Water Alternatives 3(2), 14-42.

Ritchie, H., \& Roser, M. (2020). Water use and stress. OurWorldInData.org. Pridobljeno 31. 1. 2021 s https://ourworldindata.org/water-use-stress

Save the Blue Heart of Europe News (2018). Brave women of Kruščica win court case against dam construction. Pridobljeno 15. 6. 2018 s https://balkanrivers.net/en/news/brave-women-kruščica-win-court-case-against-dam-construction

Schwarz, U. (2017). Hydropower projects on Balkan Rivers. Data Update 2017. Riverwatch and Euronatur. Fluvius Vienna. Pridobljeno 31. 1. $2021 \mathrm{~s} \mathrm{http://balkanrivers.net/sites/de-}$ fault/files/Hydropower\%20development\%20in\%20the\%20Balkans\%202017.pdf

Scudder, T. (2017). The good megadam: does it exist? The political economy of larger dams. V B. Flyvbjerg (ur.), The Oxford Handbook of Megaproject Management. Oxford: Oxford University Press.

Siciliano, G., Urban, F., Tan-Mullins, M., \& Mohan, G. (2018). Large dams, energy justice and the divergence between international, national and local developmental needs and priorities in the global South. Energy Research \& Social Science, 41. Pridobljeno 31. 1. 2021 s https://doi.org/10.1016/j.erss.2018.03.029

Sikorova, K., \& Gallop, P. (2015). Financing for hydropower in protected areas in southeast Europe. CEE Bankwatch Network. Pridobljeno 31. 1. 2021 s https://bankwatch.org/publications/financing-hydropower-protected-areas-southeast-europe

Stuckler, D., Reeves, A., Loopstra, R., Karanikolos, M., \& McKee, M. (2017). Austerity and health: the impact in the UK and Europe. European Journal of Public Health, 27(4), 18-21.

Šeremet, Z. (2018). The bridge of the brave women of Kruščica - land of absurdity. Nature for People. 30. 4. Pridobljeno 31. 1. 2021 s https://natureforpeople.org/articles/the-bridge-of-the-brave-women-of-kruscica-land-of-absurdity/

The Goldman Environmental Prize (b. d.). Medha Patkar. Pridobljeno 31. 1. $2021 \mathrm{~s} \mathrm{https://}$ www.goldmanprize.org/recipient/medha-patkar/

The Report of the World Commission on Dams (2000). Dams and development: a new framework for decision making. London, Sterling: Earthscan Publications. Pridobljeno 31. 1. 2021 s https://www.ern.org/wp-content/uploads/sites/52/2016/12/2000_world_commission_on_dams_final_report.pdf

Toman, M. J. (2013). Natura 2000 - omrežje izbranih varstvenih območij. Proteus, 76(1), 6-14.

Videmšek, B. (2020). Plan B. Ljubljana: Umco.

Združeni narodi (2019). Report of the Special Rapporteur on extreme poverty and human rights. A/HRC/41/39. Pridobljeno 29. 4. 2021 s A/HRC/41/39 - E - A/HRC/41/39 -Desktop (undocs.org) 
